\title{
Local structure and conductivity behaviour in $\mathrm{Bi}_{7} \mathrm{WO}_{13.5}$
}

A. Borowska-Centkowska, ${ }^{a *}$ M. Leszczynska, ${ }^{a}$ F. Krok, ${ }^{a}$ M. Malys, ${ }^{a}$ W. Wrobel, ${ }^{a}{ }^{\text {S.Hull }}{ }^{\mathrm{b}}$ and I. Abrahams $^{\mathrm{c}^{*}}$

${ }^{\mathrm{a}}$ Faculty of Physics, Warsaw University of Technology, ul. Koszykowa 75, 00-662, Warsaw Poland.

${ }^{\mathrm{b}}$ ISIS Facility, Rutherford Appleton Laboratory, Chilton, Didcot, Oxfordshire OX11 0QX, United Kingdom.

${ }^{c}$ Materials Research Institute, School of Biological and Chemical Sciences, Queen Mary, University of London, Mile End Road, London E1 4NS, United Kingdom

*corresponding authors:

I. Abrahams

A. Borowska-Centkowska e-mail: i.abrahams@qmul.ac.uk

e-mail: centkowska@if.pw.edu.pl 


\begin{abstract}
The structure and electrical properties of the oxide ion conductor $\mathrm{Bi}_{7} \mathrm{WO}_{13.5}$ have been examined as a function of temperature using neutron diffraction, differential thermal analysis and a.c. impedance spectroscopy. At room temperature, $\mathrm{Bi}_{7} \mathrm{WO}_{13.5}$ exhibits the type Ib tetragonally ordered fluorite structure, with tungsten distributed over two of the six cation sites. Reverse Monte Carlo (RMC) analysis of total neutron scattering data reveals a more realistic picture of the tungsten coordination environment than obtained by the average crystallographic analysis, with tungsten in predominantly tetrahedral coordination and an average bismuth coordination number of around 5 . At $893{ }^{\circ} \mathrm{C}$ on heating $\mathrm{Bi}_{7} \mathrm{WO}_{13.5}$ undergoes a phase transition to a cubic $\delta-\mathrm{Bi}_{2} \mathrm{O}_{3}$ type phase. The total scattering analysis of this phase reveals significant detail of the local environments of the cations. In particular, a bimodal distribution is found for Bi-O correlations, which has been used to guide the crystallographic analysis. Even in the type $\mathrm{Ib}$ phase $\mathrm{Bi}_{7} \mathrm{WO}_{13.5}$ shows relatively high conductivity in the intermediate temperature range and measurements of the oxide ion transference number confirm this to be virtually pure ionic in nature. Analysis of the oxide ion vacancy distributions shows a preference for $\langle 100\rangle$ vacancy pair alignment in both phases. Evidence for a second order phase transition at around $400{ }^{\circ} \mathrm{C}$ is discussed.
\end{abstract}

Keywords: Bismuth tungsten oxide, fluorite, defect structure, neutron total scattering, impedance spectroscopy. 


\section{Introduction}

Oxides that exhibit fast oxide ion conductivity have been the subject of intense research activity for many years due to their applicability as electrolytes in various electrochemical devices, such as solid oxide fuel cells (SOFCs), gas sensors and gas separation membranes. In this context, materials based on bismuth oxide show particular promise due to their exceptionally high levels of conductivity at low and intermediate temperatures. Indeed, pure $\mathrm{Bi}_{2} \mathrm{O}_{3}$ exhibits the highest known solid-state oxide-ion conductivity, in the order of $1 \mathrm{~S} \mathrm{~cm}^{-1}$, when in its $\delta$-polymorph. ${ }^{1}$ This phase shows a defect fluorite structure, consisting of cubic close packed $\mathrm{Bi}^{3+}$ cations with oxide ions located in $3 / 4$ of the tetrahedral sites. However, $\delta-\mathrm{Bi}_{2} \mathrm{O}_{3}$ only exists as a stable phase at elevated temperatures (above $\mathrm{ca} .730{ }^{\circ} \mathrm{C}$ ) and research has focused on stabilisation of this phase to ambient temperatures through solid solution formation with other oxides. ${ }^{2-6}$ In the case of solid solutions with oxides of metals exhibiting higher valency than $\mathrm{Bi}^{3+}$, distortion and/or ordering of the fluorite structure is typically observed. $^{7}$

The $\mathrm{Bi}_{2} \mathrm{O}_{3}-\mathrm{WO}_{3}$ system $\left(\mathrm{Bi}_{1-x} \mathrm{~W}_{x} \mathrm{O}_{1.5+3 x / 2}\right)$ has been studied by several authors. Takahashi and Iwahara reported very high oxide ion conductivity for fluorite structured compositions in this system. ${ }^{8}$ The first structural description of a bismuth tungstate phase was carried out by Hey et al. on the mineral russellite $\left(\mathrm{Bi}_{2} \mathrm{WO}_{6}\right){ }^{9}$, with subsequent work by other authors characterising a number of other phases in this system. ${ }^{10-15}$ Zhou classified the different fluorite ordering in bismuth-rich phases in this system into three different structural types, designated types Ia, Ib and II, occurring at different compositional ranges. ${ }^{16}$ The relationships between the structures of these ordered fluorite structures have been summarised by Ling et al. ${ }^{7,17}$

The type $\mathrm{Ib}$ structure has been reported to be adopted in the approximate compositional range $0.125 \leq x \leq 0.160^{7}$ and shows a tetragonally ordered fluorite structure with $a_{\mathrm{t}} \approx \sqrt{5} a_{\mathrm{f}}$ and $c_{\mathrm{t}} \approx$ $2 a_{\mathrm{f}}$ (where subscripts $\mathrm{t}$ and $\mathrm{f}$ denote the tetragonal and cubic fluorite structures, respectively). Watanabe et al. initially described the type $\mathrm{Ib}$ structure of $\mathrm{Bi}_{7} \mathrm{WO}_{13.15}(x=0.125)$ in space group $I 4_{1} / a{ }^{14}$ However, in subsequent studies it was shown by Zhou that the non-centrosymmetric space group $I 4_{1}$ better described electron diffraction images. ${ }^{17}$ Other subsequent studies by Nespolo et al. ${ }^{18}$ Watanabe and Ono ${ }^{19}$ and more recently by Sharma et al., ${ }^{20}$ the latter using single crystal neutron diffraction, have proposed models for the cation and anion disorder in this system. In the latter case, the type $\mathrm{Ib}$ structure was found to be adopted in a composition $(x \approx 0.122)$, which was outside the previously reported range for the solid solution and there are still some questions over aspects of the defect structure at more tungsten rich compositions.

At high temperatures, many of the compositions in the $\mathrm{Bi}_{2} \mathrm{O}_{3}-\mathrm{WO}_{3}$ system are reported to exhibit the $\delta-\mathrm{Bi}_{2} \mathrm{O}_{3}$ type structure. ${ }^{8}$ We have previously described the structure of the more bismuth rich composition, $\delta-\mathrm{Bi}_{14} \mathrm{WO}_{24}$, which was seen to show isolated tungstate tetrahedra at $800{ }^{\circ} \mathrm{C} .{ }^{21}$ 
The recent developments in total neutron scattering analysis have afforded the possibility to re-examine the type Ib structure, focusing on local order. The methodology involves extended data collection providing diffraction data sets, with excellent signal to noise ratios, that allow for accurate analysis by conventional profile fitting techniques, as well as analysis of the local order through fitting of the total scattering data, through reverse Monte Carlo (RMC) modelling. In this study, RMC modelling of total scattering data has been used to shed further light on the local ordering in the type $\mathrm{Ib}$ structure of $\mathrm{Bi}_{7} \mathrm{WO}_{13.5}$. In addition, the structure of the high temperature $\delta$ phase has been studied using the same techniques and, unusually for a $\delta$-phase, shows clear evidence of two discrete $\mathrm{Bi}-\mathrm{O}$ correlations. The electrical behaviour of $\mathrm{Bi}_{7} \mathrm{WO}_{13.15}$ is discussed in terms of the structure.

\section{Experimental}

\subsection{Preparations}

Samples of $\mathrm{Bi}_{7} \mathrm{WO}_{13.5}$ were prepared using appropriate amounts of $\mathrm{Bi}_{2} \mathrm{O}_{3}$ (Aldrich, 99.9\%) and $\mathrm{WO}_{3}$ (Aldrich, 99.99\%). Starting mixtures were ground in ethanol using a planetary ball mill and after drying were heated in a Pt crucible at $800^{\circ} \mathrm{C}$ for $24 \mathrm{~h}$, then cooled and reground. The samples were then reheated to $850{ }^{\circ} \mathrm{C}$ for $24 \mathrm{~h}$, before slow cooling to room temperature over a period of $c a$. $8 \mathrm{~h}$. For electrical measurements, powders were subsequently reground and pelletised. Pellets were pressed isostatically at a pressure of $400 \mathrm{MPa}$ and then sintered at $850{ }^{\circ} \mathrm{C}$ for $10 \mathrm{~h}$. Following sintering, samples were slow cooled in air to room temperature over a period of approximately $8 \mathrm{~h}$.

\subsection{Electrical Measurements}

Electrical characterisation was carried out by a.c. impedance spectroscopy up to $\mathrm{ca} .850{ }^{\circ} \mathrm{C}$, using a fully automated Solartron 1255/1286 system in the frequency range $1 \mathrm{~Hz}$ to $5 \times 10^{5} \mathrm{~Hz}$. Low temperature measurements were carried out on sintered pellets of $10 \mathrm{~mm}$ diameter and $c a .2$ $\mathrm{mm}$ thickness. Samples for higher temperature measurements were prepared as rectangular blocks $\left(\right.$ ca. $\left.6 \times 3 \times 3 \mathrm{~mm}^{3}\right)$ cut from slow cooled sintered pellets using a diamond saw. In both cases, platinum electrodes were sputtered by cathodic discharge. Impedance spectra were collected over two cycles of heating and cooling at stabilised temperatures. Impedance at each frequency was measured repeatedly until consistency ( $2 \%$ tolerance in drift) was achieved or a maximum number of 10 repeats had been reached, as described elsewhere. ${ }^{22}$

For measurements of transference number, a sintered pellet of approximate dimensions 17 $\mathrm{mm}$ diameter and $2 \mathrm{~mm}$ thickness was prepared, with Pt electrode dimensions of around $10 \mathrm{~mm}$ diameter. The separate ionic and electronic contributions to total conductivity were measured using 
a modified EMF method. An external adjustable voltage source was used in the concentration cell $\mathrm{O}_{2}\left(\mathrm{pO}_{2}=1.01 \times 10^{5} \mathrm{~Pa}\right): \mathrm{Pt} \mid$ oxide $\mid \mathrm{Pt}: \mathrm{O}_{2}\left(\mathrm{pO}_{2}=0.2095 \times 10^{5} \mathrm{~Pa}\right)$ and precise measurements of external current were performed, as previously described. ${ }^{23}$ D.c. voltage-current measurements were combined with in-situ a.c. impedance measurements across the cell. The separate electronic and ionic components were then used to calculate the ionic transference number $\left(t_{\text {ion }}\right)$ using eq. 1.

$$
t_{\text {ion }}=\frac{\sigma_{\text {ion }}}{\sigma_{\text {ion }}+\sigma_{\mathrm{e}}}=1-\frac{R_{\text {tot }}}{R_{\mathrm{e}}}
$$

where $R_{\text {tot }}$ is the total resistance from the impedance measurements and contains both ionic and electronic components, $R_{\mathrm{e}}$ is the electronic resistance from the EMF measurements and $\sigma_{\mathrm{ion}}$ and $\sigma_{\mathrm{e}}$ are the ionic and electronic conductivities, respectively. Data were collected on cooling between $c a$. $830{ }^{\circ} \mathrm{C}$ and $\mathrm{ca} .500{ }^{\circ} \mathrm{C}$ at stabilised temperatures.

\subsection{Differential Thermal Analysis}

The thermal behaviour was examined by differential thermal analysis (DTA) using a TA instruments Q600 scanning differential thermal analyser. Approximately $50 \mathrm{mg}$ of powdered sample in an alumina crucible was monitored over heating and cooling cycles in air between ambient temperature and $1000{ }^{\circ} \mathrm{C}$, at a rate of $20^{\circ} \mathrm{C} \mathrm{min}^{-1}$.

\subsection{Diffraction}

X-ray powder diffraction data were collected on a Philips X'Pert Pro X-ray diffractometer, fitted with an $\mathrm{X}^{\prime}$ Celerator detector, using $\mathrm{Ni}$ filtered $\mathrm{Cu}-\mathrm{K} \alpha$ radiation $\left(\lambda_{1}=1.54056 \AA\right.$ and $\lambda_{2}=$ $1.54439 \AA$ ). Room temperature data suitable for detailed Rietveld refinement were collected in the $2 \theta$ range $5-125^{\circ}$, in steps of $0.0167^{\circ}$, with a scan time of $250 \mathrm{~s}$ per step. Elevated temperature measurements were performed using an Anton-Paar HTK 1200 high temperature camera. Data were collected in flat plate $\theta / \theta$ geometry on a Pt coated sample holder. Calibration was carried out with an external Si standard. Diffraction patterns were acquired at $50{ }^{\circ} \mathrm{C}$ temperature intervals from 100 ${ }^{\circ} \mathrm{C}$ temperature up to $850^{\circ} \mathrm{C}$, over the range $5-125^{\circ} 2 \theta$, in steps of $0.033^{\circ}$, with an effective scan time of $50 \mathrm{~s}$ per step. At $900{ }^{\circ} \mathrm{C}$, an extended data collection was made using the room temperature scan parameters.

Neutron powder diffraction data were collected on the Polaris diffractometer at the ISIS Facility, Rutherford Appleton Laboratory, on back-scattering (average angle $146.72^{\circ}$ ), $90^{\circ}$ (average angle $92.59^{\circ}$ ), intermediate-angle (average angle 52.21 ), low-angle (average angle $25.99^{\circ}$ ) and very low angle (average angle $10.40^{\circ}$ ) detectors, corresponding to the approximate $d$-spacing ranges 0.04-2.6 $\AA$, 0.05-4.1 $\AA$, 0.73-7.0 $\AA$, and 0.13-13.8 $\AA$ and 0.3-48 $\AA$, respectively. The sample was 
sealed in a silica tube placed inside an $11 \mathrm{~mm}$ diameter thin walled vanadium can inside an evacuated furnace. Measurements were made at room temperature and from 300 to $900{ }^{\circ} \mathrm{C}$ in steps of $50{ }^{\circ} \mathrm{C}$. For the room temperature and $900{ }^{\circ} \mathrm{C}$ data sets, collections corresponding to proton beam charges of $c a .1350$ and $1000 \mu \mathrm{A} \mathrm{h}$, respectively, were made to allow for total scattering analysis, with shorter data sets of $30 \mu \mathrm{A} \mathrm{h}$ acquired at all other temperatures. For total scattering data correction, diffraction data were collected on an empty silica tube inside an $11 \mathrm{~mm}$ diameter thin walled (0.05 mm wall thickness) vanadium can for $c a .900 \mu \mathrm{A} \mathrm{h}$ at room temperature and $900{ }^{\circ} \mathrm{C}$.

Crystallographic structure refinement was carried out by Rietveld whole profile fitting using the program GSAS. ${ }^{24}$ For the type $\mathrm{Ib}$ structure of $\mathrm{Bi}_{7} \mathrm{WO}_{13.5}$ a combination of the parameters presented by Sharma et al. ${ }^{20}$ and Nespolo et al. ${ }^{18}$ were used as a starting model in space group $I 4_{1}$. The $z$ parameters for the M1 and M2 sites in the model were fixed at 0.0 and 0.5 , respectively to define the origin. For the high temperature $\delta$-phase structure, a cubic subcell model in space group $F m-3 m$ was used as previously described. ${ }^{25}$ A total oxide ion occupancy constraint was applied. Crystal and refinement parameters for $\mathrm{Bi}_{7} \mathrm{WO}_{13.5}$ at $20{ }^{\circ} \mathrm{C}$ and $900{ }^{\circ} \mathrm{C}$ are given in Table 1, with the corresponding fitted diffraction profiles given in the supplementary information (Figs. S1 and S2, respectively). Attempts to refine a second cubic phase at room temperature to account for the small differences in the fit to the neutron data were unsuccessful and the data presented here correspond to the single phase model. The differences seen in the X-ray fit at $900{ }^{\circ} \mathrm{C}$ are attributed to a degree of volatilization of $\mathrm{Bi}_{2} \mathrm{O}_{3}$ on extended heating in air at $900{ }^{\circ} \mathrm{C}$.

\subsection{Neutron Total Scattering Analysis}

Reverse Monte Carlo (RMC) modelling of the total neutron scattering data was used to examine the short-range ion pair correlations at $20{ }^{\circ} \mathrm{C}$ and $900{ }^{\circ} \mathrm{C}$, with the RMCProfile software. ${ }^{26}$ The program Gudrun ${ }^{27}$ was used to correct for background scattering and beam attenuation, yielding the normalized total scattering structure factors, $\mathrm{S}(Q)$, and total radial distribution function, $\mathrm{G}(r)$. Initial configurations of $5 \times 5 \times 5$ and $10 \times 10 \times 10$ unit cells for the room temperature and $900{ }^{\circ} \mathrm{C}$ structures, respectively, were used in calculations. For the type Ib structure a model based on the cation ordering determined from the Rietveld analysis was used, with a random distribution of the stoichiometric amount of $\mathrm{W}$ and $\mathrm{Bi}$ on the M1 sites. To ensure a minimum tungsten coordination number of 4 in the supercell model, the anion disorder was simplified, with the O4b anions fully occupied and the ions on the O5b site randomly selected to give the correct overall stoichiometry. For the $\delta$-phase structure, the initial model was based on the ideal fluorite structure, with cations and anions randomly distributed over sites in the supercell corresponding to the regular $4 a$ and $8 c$ crystallographic sites, respectively, in the cubic $F m-3 m$ subcell. In each case, calculations 
were performed on ten parallel configurations of different random atom distributions. Fitting was carried out against the $\mathrm{S}(Q)$ and $\mathrm{G}(r)$ data, with the Bragg profile data used to provide a constraint for the long-range crystallinity. Bond valence summation (BVS) constraints ${ }^{28}$ and an O-O potential constraint were applied during calculations. Further details on the background to the total scattering studies are discussed by Keen. ${ }^{29}$ The fitted $\mathrm{S}(Q)$ and $\mathrm{G}(r)$ data for $\mathrm{Bi}_{7} \mathrm{WO}_{13.5}$ at $20{ }^{\circ} \mathrm{C}$ and at $900{ }^{\circ} \mathrm{C}$ are given as supplementary information (Figs. S3 and S4, respectively).

\section{Results and Discussion}

\subsection{Room Temperature Structure}

The diffraction data for $\mathrm{Bi}_{7} \mathrm{WO}_{13.5}$ at room temperature were initially modelled using a combination of the parameters of Nespolo et al. ${ }^{18}$ and Sharma et al. ${ }^{20}$ The refined structural parameters and significant contact distances for $\mathrm{Bi}_{7} \mathrm{WO}_{13.5}$ at $20^{\circ} \mathrm{C}$ are given in Table 2. The O5a position, defined in the previous studies, failed to refine successfully in the present work and invariably drifted towards the O4a position, with a very large thermal parameter, yielding a physically unrealistic model. In the model of Sharma et al., the O5a position was held as part of an octahedral unit around tungsten located on the M2 site. In the present work, the failure of the O5a position to refine successfully led to its removal from the model. Attempts to locate further oxide ion positions using difference Fourier methods were unsuccessful and to preserve electroneutrality a total of 67.5 oxygen atoms per cell were required. Refinement of the site occupancies of the oxygen atom positions was inconclusive. Therefore, in the final model, the fractional occupancies of the O4b and O5b sites were fixed according to the overall stoichiometry. The slightly high isotropic thermal parameter for the oxygen atom positions reflects the positional disorder in the oxide ion sublattice, although the value is significantly lower than that for the same atoms in the work of Sharma et al. as well as the average value for these atoms in the work of Nespolo et al.

Details of the model were examined in order to establish the cation ordering. Both the models of Sharma et al. and Nespolo et al. agree that the M2 site is occupied exclusively by tungsten. In the present study this is confirmed by the short M-O contacts for this site, consistent with tungsten in tetrahedral geometry. The models of Nespolo et al. and Sharma et al. differ mainly in the location of the additional tungsten. In the model of Sharma et al. additional tungsten is located on the M1 site, which it partially occupies with bismuth, while in the model of Nespolo et al. the additional tungsten is located on the M3a site. In the present study, the M1 site shows a distorted tetrahedral geometry, which is atypical for $\mathrm{Bi}^{3+}$. This suggested that the additional tungsten was located on this site rather than the M3a site, in agreement with the model of Sharma et al. Refinement of Bi/W occupancy between the M1 and M3a sites resulted in all the additional $\mathrm{W}$ being located on the M1 site. However, the longer M1-O contacts suggest that it is still 
predominantly occupied by bismuth. In the model of Sharma et al. additional scattering seen in difference Fourier maps was interpreted as evidence for an octahedral geometry around tungsten atoms on the M1 site. This could not be confirmed using the present data.

Fig. 1 summarises the proposed coordination geometries of the $\mathrm{Bi}^{3+}$ and $\mathrm{W}^{6+}$ cations in $\mathrm{Bi}_{7} \mathrm{WO}_{13.5}$ at room temperature. The disorder of the oxide ions around the M2 site can be interpreted as two distorted tetrahedra. However, for this site to be exclusively tetrahedral the sum of the occupancies of the $\mathrm{O} 4 \mathrm{~b}$ and $\mathrm{O} 5 \mathrm{~b}$ cannot exceed 1.0. The model has been defined with higher occupancies for these sites and therefore requires tungsten to be predominantly 5 coordinate or a combination of 4 and 6 coordinate. Taking the partial occupancies into account, the average coordination number for tungsten over the M1 and M2 sites is 4.70. Bismuth atoms on the M3a, $\mathrm{M} 3 \mathrm{~b}$ and M4b sites adopt distorted octahedral, distorted square pyramidal, and "see-saw" coordination geometries, respectively. That for M4a can be interpreted as a "see-saw" or distorted square pyramidal geometry depending on the occupation of $\mathrm{O} 4 \mathrm{~b}$ and $\mathrm{O} 5 \mathrm{~b}$. Asymmetric coordination geometries are typical for $\mathrm{Bi}^{3+}$ and reflect the stereochemical activity of the $\mathrm{Bi} 6 s^{2}$ lone pair.

Examination of the individual pair correlation functions $\mathrm{g}_{i j}(r)$ (Fig. 2a) for $\mathrm{Bi}_{7} \mathrm{WO}_{13.5}$ at room temperature sheds further light on the local structure in this system. The derived coordination numbers and modal and mean contact distances are summarised in Table 3. Bismuth exhibits a coordination number of 5 , consistent with the asymmetric coordination geometries seen in Fig. 1, and compares with a value of 4.79 derived from the crystallographic analysis. The tungsten coordination number derived from the RMC analysis at 3.6 is lower than expected from the crystallographic analysis and suggests that tungsten is predominantly four coordinate. Both Bi-O and $\mathrm{W}-\mathrm{O}$ modal distances differ from the corresponding mean distances, reflecting the asymmetric distributions of the $\mathrm{Bi}-\mathrm{O}$ and $\mathrm{W}-\mathrm{O}$ pair correlations, with the mean distance longer than the mode for $\mathrm{Bi}-\mathrm{O}$ and vice versa for $\mathrm{W}-\mathrm{O}$. The mean $\mathrm{Bi}-\mathrm{O}$ distance is comparable to that obtained from the crystallographic model $(2.32 \AA)$, while that for $\mathrm{W}-\mathrm{O}$ is significantly shorter than the crystallographic average W-O distance of $2.02 \AA$. However, both the mean and modal W-O distances are close to the M2-O4a distance and may reflect a more realistic distance for tetrahedral tungsten, bearing in mind the sum of the ionic radii is $1.80 \AA$ (assuming $\mathrm{W}^{6+}$ and $\mathrm{O}^{2-}$ to be in four coordinate geometry ${ }^{30}$ ).

Fig.2b shows the metal-metal pair correlations $\mathrm{g}_{\mathrm{MM}}(r)$, with the metal next-nearest neighbours (NNN) expressed as percentages given in Table 4. For a completely random distribution these percentages should reflect the Bi:W stoichiometry, i.e. 87.5\%:12.5\%. It can be seen that while the bismuth next-nearest neighbours show a fairly random distribution, tungsten shows a preference for bismuth next-nearest neighbours. This can be seen in the relative heights of the first pair 
correlations in Fig. 2b, at around $4 \AA$. This preferential distribution of tungsten is also evident in the absence of a second W-W pair correlation at around $5.7 \AA$.

The configuration derived from the RMC analysis, uniquely allows for examination of the distribution of oxide ion vacancies in the model. By considering the type Ib structure to be derived from that of fluorite, the coordinates of all the ideal positions in a full oxide ion sublattice can readily be calculated as the centre of the tetrahedral sites in the ccp lattice. The RMC configuration can then be examined to establish which of these sites are occupied and which are vacant. The derived vacancy distribution parameters are given in Table 4. The observed tetrahedral vacancy concentration per equivalent fluorite unit cell is significantly higher than the theoretical value of 1.25 , based on the assumption that all oxide ions reside in the tetrahedral sites. The high nominal vacancy concentration reflects the cation coordination geometries observed in the crystallographic analysis, with oxide ions far away from the ideal fluorite positions, which manifests itself in the tetragonal distortion of the fluorite cell. Vacancies are preferentially found in the coordination environment of the tungsten cations, reflecting the lower coordination number of these cations, as evidenced by the significant departure of the cation nearest neighbour $(\mathrm{NN})$ percentages from the theoretical values. The cation coordination in the ideal fluorite structure can be considered to be cubic. Vacancy pairs can be aligned along the edge of the cube $\langle 100\rangle$, the face of the cube $\langle 110\rangle$ or the body diagonal of the cube $\langle 111\rangle$. A random distribution of vacancy pairs would give a 1:2:1.3 ratio of vacancy pairs. It is evident from the values given in Table 4 that there is a nonrandom distribution with a clear preference for $\langle 100\rangle$ pairs over the random situation. This preference for $\langle 100\rangle$ vacancy pairs has been seen in other undistorted fluorites such as $\mathrm{Bi}_{4} \mathrm{YbO}_{7.5}{ }^{31}$

\subsection{Thermal Behaviour}

Detail of the neutron diffraction patterns for $\mathrm{Bi}_{7} \mathrm{WO}_{13.5}$ is shown as a function of temperature in Fig. 3. The Type Ib structure appears to be maintained up to $850{ }^{\circ} \mathrm{C}$, above which temperature the structure changes to that of a cubic fluorite in space group $F m-3 m$. No evidence was seen in the diffraction patterns for phase separation at intermediate temperatures reported to occur slowly on prolonged annealing at $550{ }^{\circ} \mathrm{C} .{ }^{19}$ Fig. 4 shows the thermal variation of equivalent fluorite volume $V_{\mathrm{f}}$ and equivalent fluorite lattice parameters $a_{\mathrm{f}}$ and $c_{\mathrm{f}}$, where $a_{\mathrm{f}}$ and $c_{\mathrm{f}}$ are as defined above and $V_{\mathrm{f}}=V_{\mathrm{t}} / 10$. A linear increase in cell volume is observed up to $850{ }^{\circ} \mathrm{C}$, above which a jump to larger volume is seen, corresponding to the change from the ordered tetragonal phase to the disordered cubic phase. The increase in volume and hence decrease in density at the tetragonal to cubic transition is typical of an order-disorder transition. The equivalent fluorite lattice parameters show interesting thermal variation. While both $a_{\mathrm{f}}$ and $c_{\mathrm{f}}$ show linear thermal expansion between $c a$. 
350 and $850{ }^{\circ} \mathrm{C}$, at lower temperatures the plot for $c_{\mathrm{f}}$ exhibits a degree of curvature. Both plots show an apparent change at around $350^{\circ} \mathrm{C}$, which might be associated with a change in orientation of polyhedra. Between 600 and $650{ }^{\circ} \mathrm{C}$ the axes are approximately equal, with $a_{\mathrm{f}}$ larger than $c_{\mathrm{f}}$ above $650{ }^{\circ} \mathrm{C}$ and vice versa below ca. $600{ }^{\circ} \mathrm{C}$. At $900{ }^{\circ} \mathrm{C}, c_{\mathrm{f}}$ and $a_{\mathrm{f}}$ are again equivalent as the structure transforms to that of a cubic fluorite.

The DTA thermogram for a sample of $\mathrm{Bi}_{7} \mathrm{WO}_{13.5}$ is shown in Fig. 5. The main significant feature seen on heating is an endothermic peak with an onset temperature of $893{ }^{\circ} \mathrm{C}$ and a corresponding exothermic peak on cooling with an onset of $812{ }^{\circ} \mathrm{C}$. This can be attributed to the reversible tetragonal $\leftrightarrow$ cubic phase transition. Also noteworthy is a small change in the baseline on heating at around $400{ }^{\circ} \mathrm{C}$, which may correspond to a second order transition and appears to correlate with the change in slope seen in the $a_{\mathrm{f}}$ and $c_{\mathrm{f}}$ thermal expansion plots in Fig. 4.

The structure at $900{ }^{\circ} \mathrm{C}$ was initially modelled with both cations located on the $4 a$ site and anions distributed over three crystallographically distinct sites corresponding to the $8 c, 32 f$ and $48 i$ sites in the $F m-3 m$ cell, as seen in other substituted bismuth oxides. ${ }^{25}$ While the fit obtained was entirely satisfactory, the RMC analysis of the total scattering data (described below) revealed a bimodal distribution for $\mathrm{Bi}-\mathrm{O}$ correlations, with maxima at around 2.03 and $2.39 \AA$. These could not be explained by the crystallographic model. An alternative model for the oxide ion distribution, with ions distributed over the $32 f$ and $48 i$ sites only, did give two distinct Bi-O distances, however these were much longer than those found in the total scattering analysis. This led to the conclusion that the bismuth cations must be shifted away from the ideal $4 a$ site. Since the integrations of the two Bi-O distributions were roughly equal, this suggested that bismuth is shifted towards a face of the ideal cubic site. The W-O distribution seen in the total scattering analysis was unimodal and therefore tungsten was maintained on the ideal $4 a$ site. The refined structural parameters and significant contact distances for this model are presented in Table 5. Bismuth is found to be shifted by around $0.3 \AA$ from the centre of the ideal fluorite site.

Occupation of the $48 i$ site $(\mathrm{O} 2)$ is only seen in substituted bismuth oxides and not in pure $\delta$ $\mathrm{Bi}_{2} \mathrm{O}_{3} \cdot{ }^{32-34}$ It is therefore reasonable to assume that oxide ions on this site are associated with tungsten, as seen in $\delta-\mathrm{Bi}_{14} \mathrm{WO}_{24}{ }^{21} \mathrm{~A}$ tetrahedral coordination geometry for tungsten can be derived by coordination to four $\mathrm{O} 2$ atoms (Fig. 6). Thus an $\mathrm{O} 2$ :W ratio of 4:1 would allow for isolated tungstate tetrahedra, while lower values down to 2:1 would require sharing of these $\mathrm{O} 2$ atoms between neighbouring tungstate polyhedra. The observed ratio of 3.84:1 suggests that indeed most tungstate tetrahedra are isolated, as seen in $\delta-\mathrm{Bi}_{14} \mathrm{WO}_{24 \cdot}{ }^{21}$ As we have shown previously the coordination numbers of the bismuth cations are readily calculated. ${ }^{31}$ If it assumed that the tungstate cations are exclusively tetrahedral and associated with only $\mathrm{O} 2$, then all oxygen atoms on $\mathrm{O} 1$ sites 
are associated with bismuth. Taking the sum of the ionic radii $(2.55 \AA)$ as a cut off value, O1 coordinates 3.28 $\mathrm{Bi}$ atoms and the $\mathrm{Bi}$ coordination number can be calculated as 4.53. A proposed 5coordinate geometry for $\mathrm{Bi}$ is shown in Fig. 6. However, a number of possible coordination environments, including 4-coordinate geometries, based solely on bonds to O1, are possible.

The individual pair correlation functions derived from the $\mathrm{RMC}$ analysis of $\mathrm{Bi}_{7} \mathrm{WO}_{13.5}$ at $900{ }^{\circ} \mathrm{C}$ are shown in Fig. 7a. Particularly noticeable is the bimodal distribution associated with the Bi-O correlation, which, as mentioned above, clearly shows two distinct maxima, one centred at $c a$. $2.03 \AA$ and a second at $2.39 \AA$. While a shift in the Bi atom away from the ideal $4 a$ site in the Fm$3 m$ crystallographic cell can generate such a distribution, the mean distances seen in the crystallographic cell are larger than the modal distances in the RMC model. This bimodal distribution is particularly clear in the plot of the total pair correlation function, G(r) (Fig. S4) and we believe is the first time that this separation has been so clearly observed in a $\delta-\mathrm{Bi}_{2} \mathrm{O}_{3}$ type phase (see for example the $\mathrm{G}(r)$ plots in references 31 and 35).

The coordination numbers and mean and modal contact distances are summarised alongside those derived from the room temperature model in Table 4. The mean Bi-O contact distance from the RMC model is comparable to the average value derived from the crystallographic model (Table 5). The mean and mode W-O contact distances from the RMC model are both considerably shorter than those from the crystallographic analysis and are much closer to the sum of the ionic radii for $\mathrm{W}^{6+}$ and $\mathrm{O}^{2-}$. The coordination number for $\mathrm{Bi}$ at 4.77 is lower than at room temperature, but is similar to that seen in other substituted bismuth oxides, ${ }^{31,35}$ while that for tungsten is higher than seen at room temperature and appears to confirm a predominantly tetrahedral geometry for this cation at $900{ }^{\circ} \mathrm{C}$. The nominal tetrahedral vacancy concentration (Table 4) is much lower than at room temperature, but still significantly above the theoretical value. This is associated with significant occupation of the $48 i$ site in the crystallographic model, which lies outside the tetrahedral cavity. As seen at room temperature, the vacancy nearest neighbours are preferentially $\mathrm{W}^{6+}$ cations, while the vacancy pair distribution shows an even more marked preference for [100] aligned vacancy pairs than at room temperature. This is consistent with molecular dynamics and density functional theory calculations that show this to be the most energetically favoured configuration in the unsubstituted system $\delta-\mathrm{Bi}_{2} \mathrm{O}_{3} \cdot{ }^{36,37}$ Unlike at room temperature, there is no evidence for a preferred cation distribution, with metal next-nearest neighbours showing values close to the theoretical distribution, while the different $g_{M M}(r)$ distributions (Fig.7b) are all similar to each other. A comparison of the O-M-O angular distribution functions $\left(\mathrm{A}_{\mathrm{OMO}}(\theta)\right)$ at room temperature and $900{ }^{\circ} \mathrm{C}$ is shown in Fig. 8. The O-Bi-O angular distribution changes little between room temperature and $900{ }^{\circ} \mathrm{C}$ and shows a maximum at around $80^{\circ}$, reflecting the distorted and asymmetric coordination environments of the bismuth cations at both temperatures, as a result of 
the stereochemical activity of the $\mathrm{Bi} 6 s^{2}$ lone pairs. In contrast, there is a significant change in the $\mathrm{O}-\mathrm{W}-\mathrm{O}$ angular distribution between the two phases. At room temperature the distribution shows a maximum at around $105^{\circ}$, roughly where it would be expected for predominantly tetrahedral geometry. The situation in the cubic phase is quite different, with a maximum at around $95^{\circ}$, indicative of a significantly distorted geometry.

\subsection{Electrical Behaviour}

Impedance spectra for the title compound consisted of a semicircle due to the combined bulk and grain boundary resistances and a tail due to the blocking electrode. The bulk and grain boundary contributions could not be separated and all values quoted represent the total conductivities. Representative examples of the impedance spectra are given in the supplementary information as Fig. S5. The Arrhenius plot of total conductivity for the title compound is shown in Fig. 9. Unfortunately, the maximum temperature that could be studied with the available equipment was around $850{ }^{\circ} \mathrm{C}$, which is below the tetragonal to cubic transition temperature. The plot was fully reproducible on heating and cooling. The plot is almost linear with a slight change in slope at 400 ${ }^{\circ} \mathrm{C}$, with activation energies of $0.729(4)$ and $0.747(7) \mathrm{eV}$ at low and high temperatures, respectively and characteristic conductivities at $300{ }^{\circ} \mathrm{C}$ and $800{ }^{\circ} \mathrm{C}$ of $3.01(7) \times 10^{-4} \mathrm{~S} \mathrm{~cm}^{-1}$ and $0.11(2) \mathrm{S} \mathrm{cm}^{-1}$, respectively. The small change in activation energy roughly coincides with the changes seen in the thermal evolution of the lattice parameters (Fig. 4) and the change in baseline slope seen in the DTA (Fig. 5), which may be associated with a second order transition. Also shown in Fig. 9 are plots for other oxide ion conducting solid electrolytes. The high temperature conductivity in the type $\mathrm{Ib}$ phase at $800{ }^{\circ} \mathrm{C}$ is only about an order of magnitude smaller than reported for $\delta-\mathrm{Bi}_{2} \mathrm{O}_{3}{ }^{1}$ suggesting the influence of the ordering present in this system at this temperature is less significant than in other substituted bismuth oxides. However, the activation energy in the high temperature region is relatively high, lowering the conductivity at $600{ }^{\circ} \mathrm{C}$ to around $0.03 \mathrm{~S} \mathrm{~cm}^{-1}$, making it comparable to gadolinia doped ceria, ${ }^{38-40}$ but about an order of magnitude lower than erbium substituted bismuth oxide ${ }^{41,42}$ and $\mathrm{Dy}_{0.08} \mathrm{~W}_{0.04} \mathrm{Bi}_{0.88} \mathrm{O}_{1.56}$ (DWSB), the latter currently the best conducting substituted bismuth oxide, ${ }^{43,44}$ The lower conductivity of the W substituted system is only partly due to ordering of the fluorite lattice, with the ionic radius of the substituting cation having a significant effect, ${ }^{45-47}$ as well as the trapping of mobile vacancies in the tungsten coordination environment.

The separate contributions of ionic and electronic conductivity to total conductivity along with ionic transference number are shown as functions of temperature in Fig. 10, with values summarised in Table S1. Down to around $500{ }^{\circ} \mathrm{C}$, the lowest temperature measureable on this system, the total conductivity is seen to be predominantly ionic with transference numbers of 
around unity. A small difference is seen in the ionic and electronic activation energies with that for the electronic conductivity higher than that observed for ionic conductivity.

\section{Conclusions}

At room temperature the type $\mathrm{Ib}$ structure of $\mathrm{Bi}_{7} \mathrm{WO}_{13.5}$ shows tungsten distributed over two sites, M1 and M2, in agreement with the model of Sharma et al. ${ }^{20}$ The average tungsten coordination number of 4.70 derived from conventional crystallographic analysis would suggest a combination of 4, 5 and/or 6 coordinate tungsten. However, results from the total scattering analysis suggest a coordination number closer to 4 and contact distances much nearer the sum of the ionic radii, with $\mathrm{O}-\mathrm{W}-\mathrm{O}$ angles close to that expected for tetrahedral geometry. The discrepancy illustrates the difficulty in accurately modelling the relatively low tungsten content of the system in the crystallographic analysis. Bismuth is found to exhibit a coordination number of around 5 and the crystallographic analysis reveals a number of asymmetric coordination geometries consistent with stereochemical activity of the $\mathrm{Bi} 6 s^{2}$ lone pair.

On heating, a weak effect is seen in the DTA thermogram at around $400{ }^{\circ} \mathrm{C}$, which may be associated with a second order transition and is reflected in changes seen in the thermal evolution of lattice parameters and the electrical behaviour. This transition is subtle with little obvious change in structure and may involve a reorientation of polyhedra in the type Ib structure. The type Ib structure is maintained up to around $850{ }^{\circ} \mathrm{C}$, with a transition to a cubic $\delta-\mathrm{Bi}_{2} \mathrm{O}_{3}$ type phase at $893{ }^{\circ} \mathrm{C}$. While the diffraction patterns for the structure at $900{ }^{\circ} \mathrm{C}$ can be interpreted using a standard fluorite model, the RMC fits to the total scattering data reveal a clear bimodal distribution for $\mathrm{Bi}-\mathrm{O}$ correlations. This has led to the conclusion that in this phase bismuth atoms are shifted away from the regular $4 a$ site of the ccp lattice, lowering the coordination number slightly compared to that in the type $\mathrm{Ib}$ structure.

Tungsten is found to be predominantly four coordinate in the $\delta$-phase, with randomly distributed distorted tungstate tetrahedra. In common with other substituted bismuth oxides, there is a preference for $\langle 100\rangle$ oxide ion vacancy pair alignment in the $\delta$-phase, consistent with studies that show this to be the most energetically favoured alignment. Interestingly, this preference is also seen in the ordered type Ib phase, but is less marked, suggesting a similar conduction mechanism.

Type $\mathrm{Ib} \mathrm{Bi}_{7} \mathrm{WO}_{13.5}$ is an almost pure ionic conductor above $500{ }^{\circ} \mathrm{C}$, with values of conductivity at $600{ }^{\circ} \mathrm{C}$ comparable to gadolinia doped ceria, but lower than the best substituted bismuth oxides. The lower conductivity of tungsten substituted system compared to other substituted bismuth oxides is attributed not only to ordering of the fluorite structure, but to the size of the substituent cation and the reduction of the mobile vacancy concentration 


\section{Acknowledgements}

We gratefully acknowledge the STFC ISIS Facility for neutron beam time and Dr Ron I. Smith for his assistance. The National Science Centre, Poland is thanked for funding to ABC (grant No. 2011/01/N/ST5/03263) and to ML (grant no. DEC-2012/05/N/ST5/01891).

\section{References}

1. T. Takahashi, H. Iwahara and Y. Nagaj, J. Appl. Electrochem., 1972, 2, 97.

2. G. Mairesse, in Fast Ion Transport in Solids, B. Scrosati, A. Magistris, C.M. Mari, G. Mariotto (Eds.), Kluwer Academic Publishers, Dordrecht, 1993, p271.

3. J.C. Boivin and G. Mairesse, Chem. Mater., 1998, 10, 2870.

4. P. Shuk, H.D. Wiemhöfer, U. Guth, W. Göpel and M. Greenblatt, Solid State Ionics, 1996, 89, 179.

5. N.M. Sammes, G.A. Tompsett, H. Näfe and F. Aldinger, J. Eur. Ceram. Soc., 1999, 19, 1801.

6. A.M. Azad, S. Larose nd S.A. Akbar, J. Mater. Sci., 1994, 29, 4135.

7. C.D. Ling, R.L. Withers, S. Schmid and J.G. Thompson, J. Solid State Chem., 1998, 137, 42.

8. T. Takahashi and H. Iwahara, J. Appl. Electrochem., 1973, 3, 65.

9. M. Hey, F. Bannister and A. Russell, Mineral. Mag., 1938, 25, 41.

10. L.G. Sillen and K. Lundborg, Ark. Kemi. Mineral. Geol., 1943, 17A, 1.

11. N.P. Smolyaninov and L.N. Belyaev, Zh. Neorg. Khim., 1962, 7, 2591.

12. E.L. Gal'Perin, L.Y. Erman, I.K. Kolchin, M.A. Belova and K.S. Chemyshev, Zh. Neorg.

Khim., 1966, 11, 2125.

13. E.L. Speranskaya, Izv. Akad. Nauk. SSSR Neorg. Mater., 1970, 6, 18.

14. A. Watanabe, N. Ishizwa and M. Kato, J. Solid State Chem., 1985, 60, 252.

15. S.N. Hoda and L.L.Y. Chang, J. Am. Ceram. Soc., 1974, 57, 323.

16. W. Zhou, J. Solid State Chem., 1994, 108, 381.

17. C.D. Ling, J. Solid State Chem., 1999, 148, 380.

18. M. Nespolo, A. Watanabe and Y. Suetsugu, Cryst. Res. Technol., 2002, 37, 414.

19. A. Watanabe and A. Ono, Solid State Ionics, 2004, 174, 15.

20. N. Sharma, R. B. Macquart, M. Avdeev, M. Christensen, G. J. McIntyre, Y. Chene and

C. D. Ling, Acta Crytallogr. Sect B Struct. Sci., 2010, 66, 165.

21. A. Borowska-Centkowska, F. Krok, I. Abrahams, W. Wrobel, J.R. Dygas and S. Hull, Solid State Ionics, 2011, 202, 14.

22. J.R. Dygas, P. Kurek and M.W. Breiter, Electrochim. Acta, 1995, 40, 1545. 
23. M. Malys, J.R. Dygas, M. Holdynski, A. Borowska-Centkowska, W. Wrobel and M. Marzantowicz, Solid State Ionics, 2012, 225, 493.

24. A. C. Larson and R. B. Von Dreele, Los Alamos National Laboratory Report, No. LAUR-86$748,1987$.

25. I. Abrahams, A. Kozanecka-Szmigiel, F. Krok, W. Wrobel, S.C.M. Chan, and J.R. Dygas, Solid State Ionics, 2006, 177, 1761.

26. M.G. Tucker, D.A. Keen, M.T. Dove, A.L. Goodwin and Q. Hui, J. Phys.: Condens. Matter, 2007, 19, 335218.

27. A. K. Soper, GudrunN and GudrunX : programs for correcting raw neutron and X-ray diffraction data to differential scattering cross section, Report RAL-TR-2011-013, Rutherford Appleton Laboratory Technical, 2011.

28. S.T. Norberg, M.G. Tucker and S. Hull, J. Appl. Crystallogr., 2009, 42, 179.

29. D. A. Keen, J. Appl. Cryst., 2001, 34, 172.

30. R.D. Shannon, Acta Crystallogr., 1976, A32, 751.

31. M. Leszczynska, X. Liu, W. Wrobel, M. Malys, M. Krynski, S.T. Norberg, S. Hull, F. Krok and I. Abrahams, Chem. Mater., 2013, 25, 326.

32. P.D. Battle, C.R.A. Catlow, J. Drennan and A.D. Murray, J. Phys. C, 1983, 16, 561.

33. S. Hull, S.T. Norberg, M.G. Tucker, S.G. Eriksson, C.E. Mohn and S. Stølen, Dalton Trans. $2009,8737$.

34. M. Yashima and D. Ishimura, Chem. Phys. Lett., 2003, 378, 395.

35. I. Abrahams, X. Liu, S. Hull, S.T. Norberg, F. Krok, A. Kozanecka-Szmigiel, M. S. Islam and S.J. Stokes, Chem. Mater., 2010, 22, 4435.

36. D.S. Aidhy, J.C. Nino, S.B. Sinnot, E.D. Wachsman and S.R. Phillpot, J. Am. Ceram. Soc., 2008, 91, 2349.

37. A. Walsh and G.W. Watson, Phys. Rev. B, 2006, 73, 235104.

38. B.C.H. Steele, Solid State Ionics, 2000, 129, 95.

39. K.R. Reddy and K. Karan, J. Electroceram., 2005, 15, 45.

40. S. Omar, E.D. Wachsman and J.C. Nino, Solid State Ionics, 2006, 177, 3199.

41. M.J. Verkerk, K. Keizer and A.J. Burggraaf, J. Appl. Electrochem., 1980, 10, 81.

42. M.J. Verkerk and A.J. Burggraaf., J Electrochem. Soc. 1981, 128, 75.

43. D.W. Jung, K.L. Duncan and E.D. Wachsman, Acta Materialia, 2010, 58, 355.

44. E.D. Wachsman and K.T. Lee, Science, 2011, 334, 935.

45. D.J. Kim, J. Am. Ceram. Soc. 1989, 72, 1415.

46. J.A. Kilner and R.J. Brook, Solid State Ionics, 1982, 6, 237.

47. N. Jiang, E.D. Wachsman and S. Jung, Solid State Ionics, 2002, 150, 347. 


\section{Table 1}

Crystal and refinement parameters for $\mathrm{Bi}_{7} \mathrm{WO}_{13.5}$ at $20^{\circ} \mathrm{C}$ and $900{ }^{\circ} \mathrm{C}$. Estimated standard deviations are given in parentheses.

\begin{tabular}{|c|c|c|c|}
\hline \multicolumn{2}{|c|}{ Temperature $\left({ }^{\circ} \mathrm{C}\right)$} & 20 & 900 \\
\hline \multicolumn{2}{|c|}{ Chemical formula } & $\mathrm{Bi}_{0.875} \mathrm{~W}_{0.125} \mathrm{O}_{1.6875}$ & $\mathrm{Bi}_{0.875} \mathrm{~W}_{0.125} \mathrm{O}_{1.6875}$ \\
\hline \multicolumn{2}{|l|}{$M_{r}\left(\mathrm{~g} \mathrm{~mol}^{-1}\right)$} & 232.84 & 232.84 \\
\hline \multicolumn{2}{|l|}{ Crystal system } & Tetragonal & Cubic \\
\hline \multicolumn{2}{|l|}{ Space group } & $I 4_{1}$ & $F m-3 m$ \\
\hline \multicolumn{2}{|c|}{ Lattice parameter(s) $(\AA)$} & $12.5196(2) \mathrm{c}=11.2332(2)$ & $5.69105(6)$ \\
\hline \multicolumn{2}{|l|}{ Volume $\left(\AA^{3}\right)$} & 1760.70(6) & $184.322(5)$ \\
\hline \multicolumn{2}{|l|}{$Z$} & 40 & 4 \\
\hline \multicolumn{2}{|c|}{ Density (calc) $\mathrm{g} \mathrm{cm}^{-3}$} & 8.784 & 8.391 \\
\hline \multirow{14}{*}{$\mathrm{R}$-factors ${ }^{a}$} & \multirow{4}{*}{$\begin{array}{l}\text { Neutron back } \\
\text { scattering }\end{array}$} & $\mathrm{R}_{\mathrm{wp}}=0.0135$ & $\mathrm{R}_{\mathrm{wp}}=0.0060$ \\
\hline & & $R_{p}=0.0233$ & $R_{p}=0.0088$ \\
\hline & & $\mathrm{R}_{\mathrm{ex}}=0.0046$ & $\mathrm{R}_{\mathrm{ex}}=0.0053$ \\
\hline & & $\mathrm{R}_{\mathrm{F}} 2=0.0966$ & $\mathrm{R}_{\mathrm{F}} 2=0.0327$ \\
\hline & \multirow{4}{*}{ Neutron $90^{\circ}$} & $\mathrm{R}_{\mathrm{wp}}=0.0135$ & $\mathrm{R}_{\mathrm{wp}}=0.0095$ \\
\hline & & $\mathrm{R}_{\mathrm{p}}=0.0242$ & $R_{p}=0.0150$ \\
\hline & & $\mathrm{R}_{\mathrm{ex}}=0.0030$ & $\mathrm{R}_{\mathrm{ex}}=0.0035$ \\
\hline & & $\mathrm{R}_{\mathrm{F}} 2=0.1193$ & $\mathrm{R}_{\mathrm{F}} 2=0.1808$ \\
\hline & \multirow{4}{*}{ X-ray } & $\mathrm{R}_{\mathrm{wp}}=0.0725$ & $\mathrm{R}_{\mathrm{wp}}=0.0458$ \\
\hline & & $R_{p}=0.0431$ & $\mathrm{R}_{\mathrm{p}}=0.0300$ \\
\hline & & $\mathrm{R}_{\mathrm{ex}}=0.0237$ & $\mathrm{R}_{\mathrm{ex}}=0.0216$ \\
\hline & & $\mathrm{R}_{\mathrm{F}} 2=0.2111$ & $\mathrm{R}_{\mathrm{F}} 2=0.2455$ \\
\hline & \multirow{2}{*}{ Totals } & $\mathrm{R}_{\mathrm{wp}}=0.0168$ & $\mathrm{R}_{\mathrm{wp}}=0.0146$ \\
\hline & & $\mathrm{R}_{\mathrm{p}}=0.0430$ & $\mathrm{R}_{\mathrm{p}}=0.0299$ \\
\hline \multicolumn{2}{|c|}{ No. of variables } & 157 & 99 \\
\hline \multicolumn{2}{|l|}{$\chi^{2}$} & 11.98 & 4.385 \\
\hline \multirow{3}{*}{$\begin{array}{l}\text { No of profile } \\
\text { points }\end{array}$} & Neut. (bs) & 2150 & 1714 \\
\hline & Neut. $\left(90^{\circ}\right)$ & 1866 & 1475 \\
\hline & X-ray & 3440 & 6282 \\
\hline \multirow{3}{*}{$\begin{array}{l}\text { No. of } \\
\text { reflections }\end{array}$} & Neut. (bs) & 2644 & 23 \\
\hline & Neut. $\left(90^{\circ}\right)$ & 2709 & 19 \\
\hline & X-ray & 1498 & 33 \\
\hline
\end{tabular}


Table 2

Refined structural parameters and significant contact distances $(\AA)$ for $\mathrm{Bi}_{7} \mathrm{WO}_{13.5}$ at $20{ }^{\circ} \mathrm{C}$.

Estimated standard deviations are given in parentheses.

(a) Atomic parameters

\begin{tabular}{|l|l|l|l|l|l|l|}
\hline Atom & Site & $x$ & $y$ & $z$ & Occ. & $\mathrm{U}_{\text {iso }}\left(\AA^{2}\right)$ \\
\hline M1 (Bi/W) & $4 a$ & 0.0 & 0.0 & 0.0 & $0.75 / 0.25$ & $0.0265(4)$ \\
\hline M2 (W) & $4 a$ & 0.0 & 0.0 & 0.5 & 1.0 & $0.0265(4)$ \\
\hline M3a (Bi) & $8 b$ & $0.2901(6)$ & $0.1013(6)$ & $0.9797(12)$ & 1.0 & $0.0265(4)$ \\
\hline M3b (Bi) & $8 b$ & $0.7086(7)$ & $0.3916(6)$ & $0.2647(11)$ & 1.0 & $0.0265(4)$ \\
\hline M4a (Bi) & $8 b$ & $0.2002(6)$ & $0.4016(5)$ & $-0.0004(11)$ & 1.0 & $0.0265(4)$ \\
\hline M4b (Bi) & $8 b$ & $0.7941(6)$ & $0.1041(6)$ & $0.2339(11)$ & 1.0 & $0.0265(4)$ \\
\hline O1a & $8 b$ & $0.1553(11)$ & $0.0571(11)$ & $0.1012(15)$ & 1.0 & $0.0576(7)$ \\
\hline O1b & $8 b$ & $0.8472(11)$ & $0.4236(10)$ & $0.1553(17)$ & 1.0 & $0.0576(7)$ \\
\hline O2a & $8 b$ & $0.0603(12)$ & $0.3294(10)$ & $0.0867(17)$ & 1.0 & $0.0576(7)$ \\
\hline O2b & $8 b$ & $0.9364(12)$ & $0.1790(9)$ & $0.1656(16)$ & 1.0 & $0.0576(7)$ \\
\hline O3a & $8 b$ & $0.2593(11)$ & $0.2886(9)$ & $0.1336(16)$ & 1.0 & $0.0576(7)$ \\
\hline O3b & $8 b$ & $0.7384(10)$ & $0.2227(10)$ & $0.1097(16)$ & 1.0 & $0.0576(7)$ \\
\hline O4a & $8 b$ & $0.3990(9)$ & $0.0665(9)$ & $0.1634(12)$ & 1.00 & $0.0576(7)$ \\
\hline O4b & $8 b$ & $0.5333(14)$ & $0.3833(14)$ & $0.1216(15)$ & 0.719 & $0.0576(7)$ \\
\hline O5b & $8 b$ & $0.3888(14)$ & $0.4602(15)$ & $0.1229(15)$ & 0.719 & $0.0576(7)$ \\
\hline
\end{tabular}

(b) Contact distances

\begin{tabular}{|l|l|l|l|l|l|}
\hline M1-O1a & $2.363(14) \times 2$ & M1-O1b & $2.389(16) \times 2$ & M2-O4a & $1.800(11) \times 2$ \\
\hline M2-O4b & $2.043(17) \times 2$ & M2-O5b & $2.023(17) \times 2$ & M3a-O1a & $2.240(16)$ \\
\hline M3a-O1a' & $2.490(15)$ & M3a-O2a & $2.254(17)$ & M3a-O2b & $2.220(18)$ \\
\hline M3a-O3a & $2.460(14)$ & M3a-O4a & $2.512(13)$ & M3b-O1b & $2.163(15)$ \\
\hline M3b-O1b' & $2.355(15)$ & M3b-O2a & $2.311(17)$ & M3b-O2b & $2.274(16)$ \\
\hline M3b-O3b & $2.358(16)$ & M4a-O2a & $2.200(17)$ & M4a-O3a & $2.195(14)$ \\
\hline M4a-O3a' & $2.211(15)$ & M4a-O4b & $2.424(19)$ & M4a-O5b & $2.465(19)$ \\
\hline M4b-O1a & $2.587(15)$ & M4b-O2b & $2.154(18)$ & M4b-O3b & $2.154(14)$ \\
\hline M4b-O3b' & $2.207(15)$ & \multicolumn{5}{|l}{} \\
\cline { 1 - 4 } & & &
\end{tabular}


Table 3

M-O coordination numbers $(\mathrm{CN})$ and modal and mean M-O contact distances $(\AA)$ from RMC analysis of $\mathrm{Bi}_{7} \mathrm{WO}_{13.5}$ at 20 and $900{ }^{\circ} \mathrm{C}$. Values are averages of 10 parallel calculations and standard deviations are given in parentheses. M-O distances and coordination numbers were calculated up to a maximum of $2.75 \AA$ and $1.91 \AA$ at $20^{\circ} \mathrm{C}$ and $2.75 \AA$ and $2.23 \AA$ at $900{ }^{\circ} \mathrm{C}$ for Bi-O and W-O correlations, respectively.

\begin{tabular}{|c|c|c|c|}
\hline \multicolumn{2}{|c|}{} & $20{ }^{\circ} \mathrm{C}$ & $900{ }^{\circ} \mathrm{C}$ \\
\hline \multirow{4}{*}{$\mathrm{CN}$} & Bi-O & $5.01(3)$ & $4.711(6)$ \\
\cline { 2 - 4 } & W-O & $3.60(3)$ & $4.38(3)$ \\
\hline \multirow{5}{*}{ Distances } & Bi-O Mode & $2.165(3)$ & $2.027(4)$ \\
\cline { 2 - 4 } & Bi-O Mean & $2.309(3)$ & $2.310(1)$ \\
\cline { 2 - 4 } & W-O Mode & $1.85(8)$ & $1.89(9)$ \\
\cline { 2 - 4 } & W-O Mean & $1.786(1)$ & $1.897(1)$ \\
\cline { 2 - 4 } & Wt. Av. M-O Mode & $2.13(1)$ & $2.01(1)$ \\
\cline { 2 - 4 } & Wt. Av. M-O Mean & $2.442(2)$ & $2.258(1)$ \\
\hline
\end{tabular}

Table 4

Defect concentration and distribution parameters derived from $\mathrm{RMC}$ analyses of $\mathrm{Bi}_{7} \mathrm{WO}_{13.5}$ at 20 and $900{ }^{\circ} \mathrm{C}$. Values are averages of 10 parallel calculations and standard deviations are given in parentheses.

\begin{tabular}{|c|c|c|c|}
\hline & $20{ }^{\circ} \mathrm{C}$ & $900{ }^{\circ} \mathrm{C}$ & Theoretical \\
\hline $\begin{array}{c}\text { No. tet. vacancies } \\
\text { per fluorite cell }\end{array}$ & $2.81(2)$ & $2.12(4)$ & 1.25 \\
\hline $100: 110: 111$ & $1.00: 1.78: 1.09$ & $1.00: 1.60: 1.09$ & $1.0: 2.0: 1.3$ \\
\hline$\% \mathrm{vac}(\mathrm{NN})_{\mathrm{Bi}}$ & $63.5(1)$ & $70.9(4)$ & 87.5 \\
\hline$\% \mathrm{vac}(\mathrm{NN})_{\mathrm{W}}$ & $36.5(1)$ & $29.1(4)$ & 12.5 \\
\hline$\% \mathrm{Bi}(\mathrm{NNN})_{\mathrm{Bi}}$ & $86.97(4)$ & $87.12(8)$ & 87.5 \\
\hline$\% \mathrm{Bi}(\mathrm{NNN})_{\mathrm{W}}$ & $13.03(4)$ & $12.88(8)$ & 12.5 \\
\hline$\% \mathrm{~W}(\mathrm{NNN})_{\mathrm{Bi}}$ & $93.5(1)$ & $88.6(4)$ & 87.5 \\
\hline$\% \mathrm{~W}(\mathrm{NNN})_{\mathrm{W}}$ & $6.5(1)$ & $11.4(4)$ & 12.5 \\
\hline
\end{tabular}


Table 5

Refined Structural parameters and significant contact distances $(\AA)$ for $\mathrm{Bi}_{0.875} \mathrm{~W}_{0.125} \mathrm{O}_{1.6875}$ at $900{ }^{\circ} \mathrm{C}$. Estimated standard deviations are given in parentheses.

(a) Atomic parameters

\begin{tabular}{|l|l|l|l|l|l|l|}
\hline Atom & Site & $x$ & $y$ & $z$ & Occ. & $\mathrm{U}_{\text {iso }}\left(\AA^{2}\right)$ \\
\hline $\mathrm{Bi}$ & $24 e$ & $0.0555(16)$ & 0.0 & 0.0 & 0.14583 & $0.048(3)$ \\
\hline $\mathrm{W}$ & $4 a$ & 0.0 & 0.0 & 0.0 & 0.125 & $0.048(3)$ \\
\hline $\mathrm{O} 1$ & $32 f$ & $0.2905(4)$ & $0.2905(4)$ & $0.2905(4)$ & $0.151(1)$ & $0.106(2)$ \\
\hline $\mathrm{O} 2$ & $48 i$ & 0.5 & $0.1620(10)$ & $0.1620(10)$ & $0.040(1)$ & $0.106(2)$ \\
\hline
\end{tabular}

(b) Contact distances

\begin{tabular}{|c|c|c|c|c|c|}
\hline $\mathrm{Bi}-\mathrm{O} 1$ & $2.152(6) \times 4$ & $\mathrm{Bi}-\mathrm{O} 1^{\prime \prime \prime \prime}$ & $2.693(6) \times 4$ & $\mathrm{Bi}-\mathrm{O} 2^{\prime \prime \prime}$ & $2.287(6) \times 4$ \\
\hline Bi-O1' & $2.219(4) \times 8$ & $\mathrm{Bi}-\mathrm{O} 2$ & $1.853(8) \times 4$ & $\mathrm{Bi}-\mathrm{O} 2^{\prime \prime \prime \prime}$ & $2.422(10) \times 4$ \\
\hline Bi-O1" & $2.536(6) \times 8$ & $\mathrm{Bi}-\mathrm{O} 2^{\prime}$ & $2.017(4) \times 4$ & $\mathrm{Bi}-\mathrm{O} 2^{\prime \prime \prime \prime \prime \prime}$ & $2.846(10) \times 4$ \\
\hline $\mathrm{Bi}-\mathrm{O} 1^{\prime \prime \prime}$ & $2.592(7) \times 4$ & $\mathrm{Bi}-\mathrm{O} 2^{\prime \prime}$ & $2.156(3) \times 8$ & Av. Bi-O & $2.37(4)$ \\
\hline W-O1 & $2.3615(7) \times 24$ & $\mathrm{~W}-\mathrm{O} 2$ & $2.133(3) \times 24$ & Av. W-O & $2.300(1)$ \\
\hline
\end{tabular}




\section{Figure Captions}

Fig. 1. Cation coordination geometries in $\mathrm{Bi}_{7} \mathrm{WO}_{13.5}$ at room temperature. Bismuth (yellow), tungsten (blue) and oxygen (red) atoms are indicated. Dashes indicate bonds to partially occupied sites.

Fig. 2. Pair correlation functions $\mathrm{g}_{\mathrm{ij}}(r)$ derived from $\mathrm{RMC}$ analysis of neutron data for $\mathrm{Bi}_{7} \mathrm{WO}_{13.5}$ at room temperature: (a) $\mathrm{g}_{\mathrm{MO}}(r)$ and (b) $\mathrm{g}_{\mathrm{MM}}(r)$.

Fig. 3. Thermal variation of neutron diffraction patterns for $\mathrm{Bi}_{7} \mathrm{WO}_{13.5}$. Back scattering data are shown.

Fig. 4. Thermal variation of (a) equivalent fluorite unit cell volume and (b) equivalent fluorite lattice parameters $a_{\mathrm{f}}$ and $c_{\mathrm{f}}$. Error bars are smaller than the symbols used.

Fig. 5. DTA thermogram for $\mathrm{Bi}_{7} \mathrm{WO}_{13.5}$.

Fig.6. Proposed cation coordination geometries in $\mathrm{Bi}_{7} \mathrm{WO}_{13.5}$ at $900{ }^{\circ} \mathrm{C}$. Bismuth (yellow), tungsten (blue) and oxygen (red) atoms are indicated.

Fig. 7. Pair correlation functions $\mathrm{g}_{\mathrm{ij}}(r)$ derived from $\mathrm{RMC}$ analysis of neutron data for $\mathrm{Bi}_{7} \mathrm{WO}_{13.5}$ at $900{ }^{\circ} \mathrm{C}$ : (a) $\mathrm{g}_{\mathrm{MO}}(r)$ and $(\mathrm{b}) \mathrm{g}_{\mathrm{MM}}(r)$.

Fig. 8. Angular distribution functions $\mathrm{A}_{\mathrm{OMO}}(r)$ for $\mathrm{Bi}_{7} \mathrm{WO}_{13.5}$ at $20{ }^{\circ} \mathrm{C}$ and $900{ }^{\circ} \mathrm{C}$.

Fig. 9. Arrhenius plot of total conductivity for $\mathrm{Bi}_{7} \mathrm{WO}_{13.5}$. Data correspond to the second cooling run and are compared to those from various solid oxide electrolytes reported in the literature as indicated: erbium stabilized bismuth oxide $\left(\mathrm{ESB}, \mathrm{Er}_{0.4} \mathrm{Bi}_{1.6} \mathrm{O}_{3}\right)$, dysprosium tungsten stabilized bismuth oxide (DWSB, Dy ${ }_{0.08} \mathrm{~W}_{0.04} \mathrm{Bi}_{0.88} \mathrm{O}_{1.56}$ ), gadolinium doped ceria (GDC, $\mathrm{Gd}_{0.1} \mathrm{Ce}_{0.9} \mathrm{O}_{1.95}$ ) and $\mathrm{Bi}_{2} \mathrm{O}_{3}$ on heating. ${ }^{44,42}$

Fig. 10. Temperature dependence of ionic and electronic conductivities in $\mathrm{Bi}_{7} \mathrm{WO}_{13.5}$. 


\section{Local structure and conductivity behaviour in $\mathrm{Bi}_{7} \mathrm{WO}_{13.5}$}

A. Borowska-Centkowska, M. Leszczynska, F. Krok, M. Malys, W. Wrobel, S.Hull and I. Abrahams

\section{Supplementary Information}


(a)

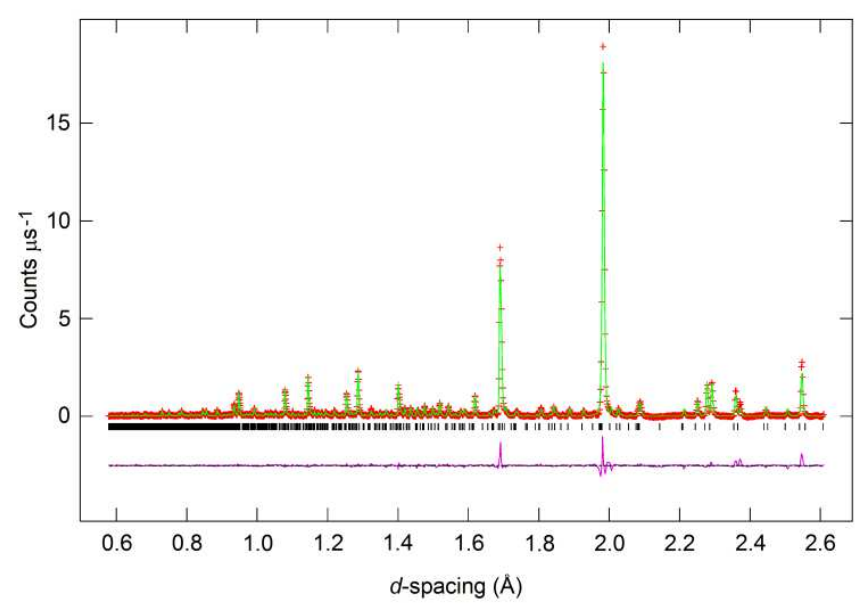

(b)

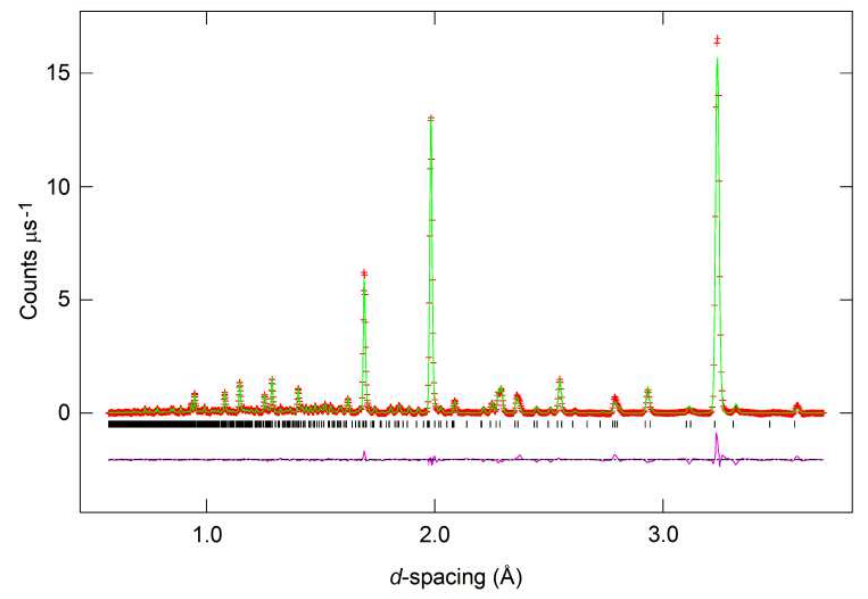

(c)

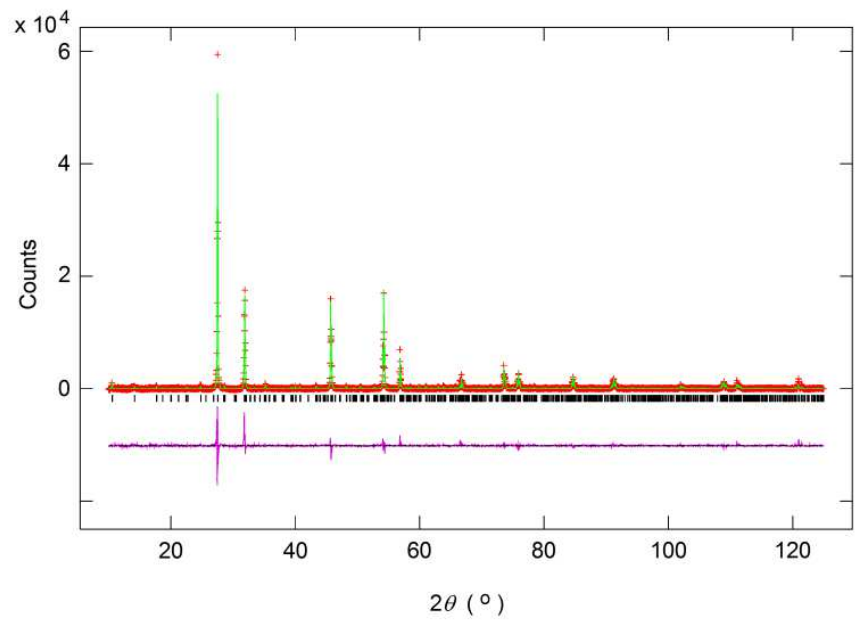

Fig. S1. Diffraction profiles for $\mathrm{Bi}_{7} \mathrm{WO}_{13.5}$ at room temperature showing (a) neutron back scattering (b) neutron $90^{\circ}$ and (c) X-ray data, fitted by conventional Rietveld analysis. Observed (crosses), calculated (line) and difference (lower) profiles are shown, with reflection positions indicated by markers. 
(a)

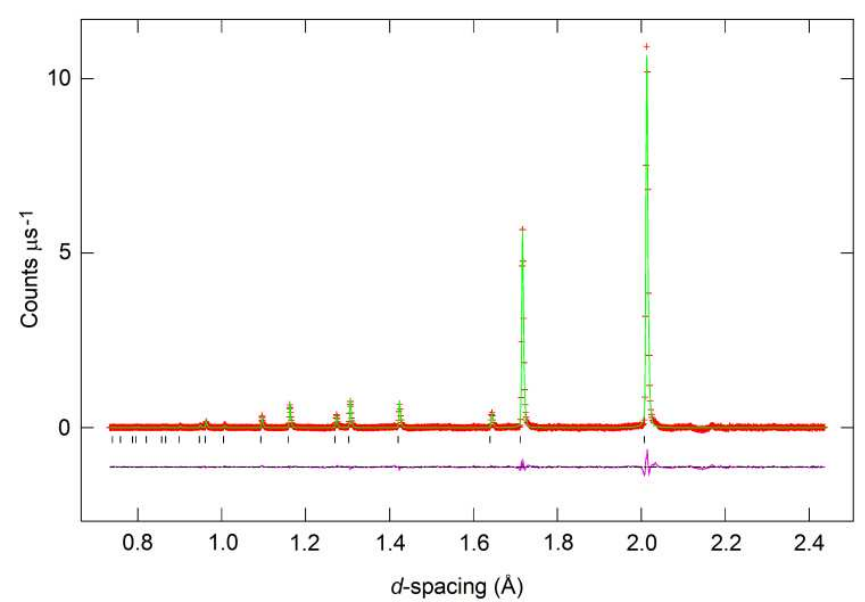

(b)

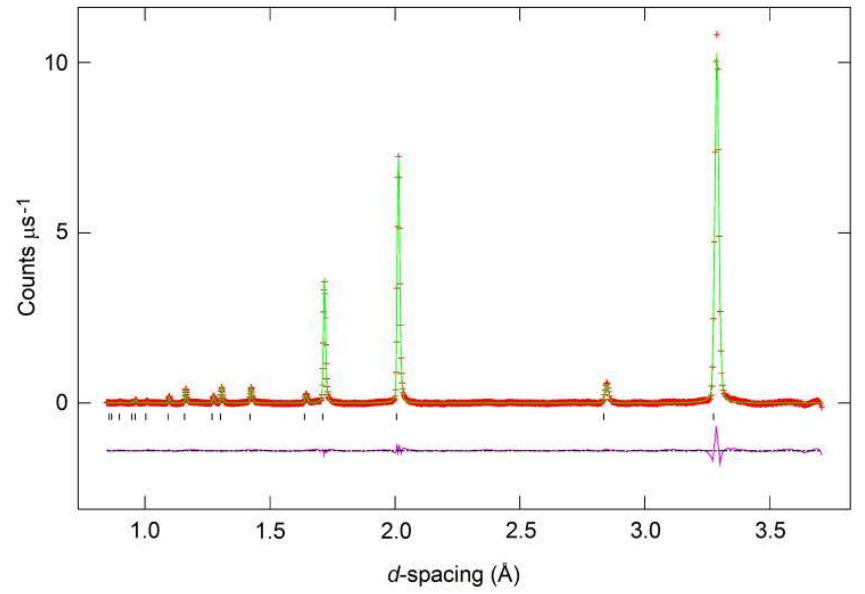

(c)

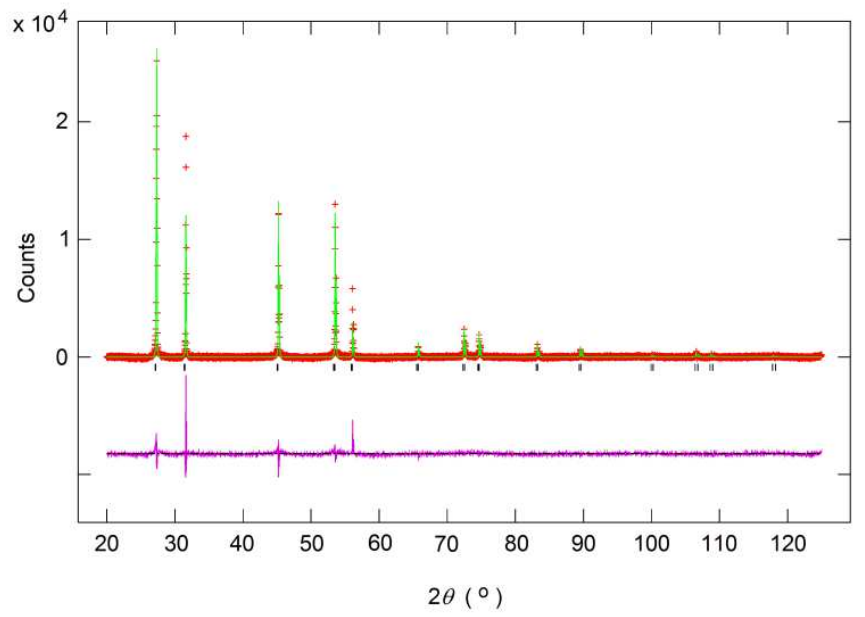

Fig. S2. Diffraction profiles for $\mathrm{Bi}_{7} \mathrm{WO}_{13.5}$ at $900{ }^{\circ} \mathrm{C}$ showing (a) neutron back scattering (b) neutron $90^{\circ}$ and (c) X-ray data, fitted by conventional Rietveld analysis. Observed (crosses), calculated (line) and difference (lower) profiles are shown, with reflection positions indicated by markers. 
(a)

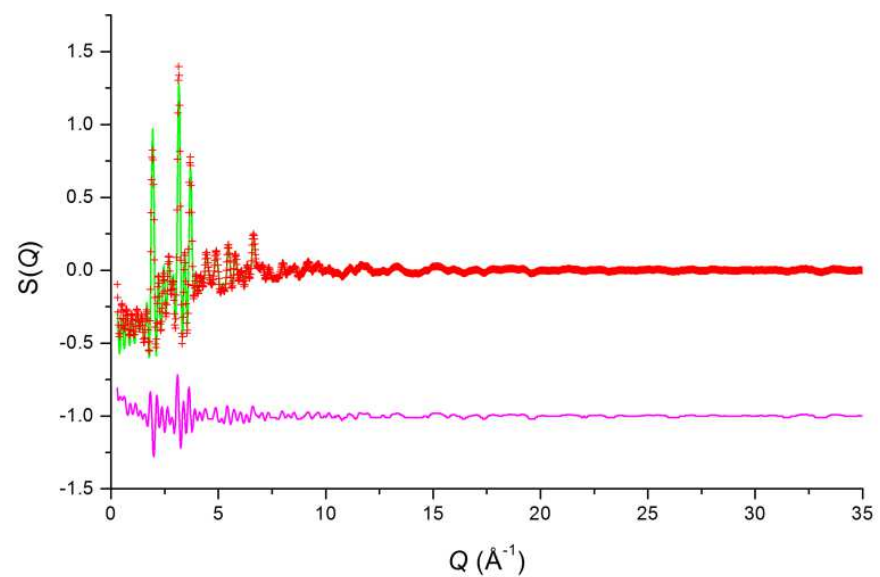

(b)

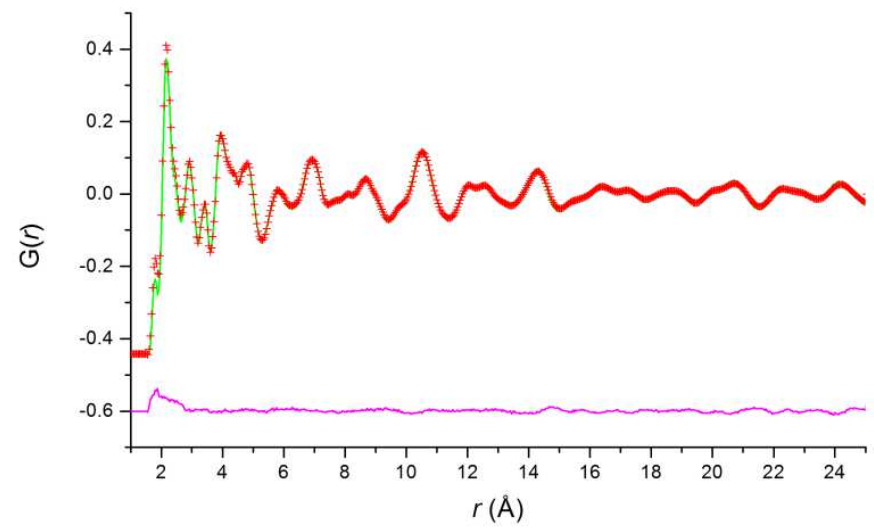

Fig. S3. (a) Neutron total scattering, $\mathrm{S}(Q)$, and (b) neutron total pair correlation, $\mathrm{G}(r)$, data for $\mathrm{Bi}_{7} \mathrm{WO}_{13.5}$ at room temperature, fitted by RMC analysis. Observed (crosses), calculated (line) and difference (lower) profiles are shown. 
(a)

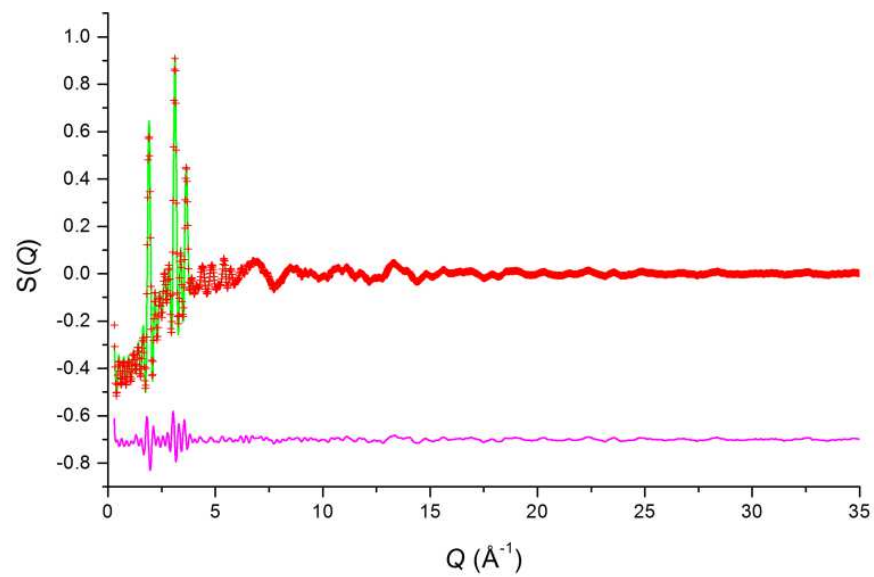

(b)

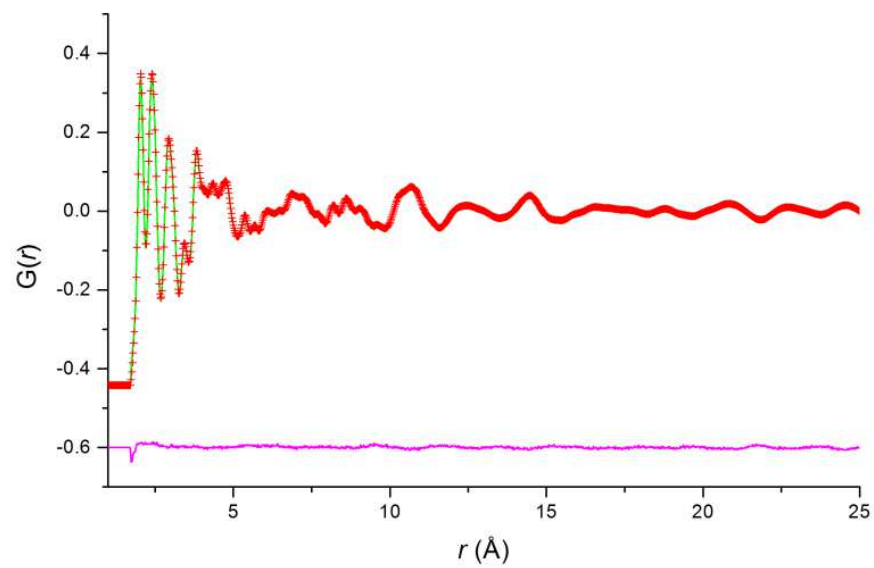

Fig. S4. (a) Neutron total scattering, $\mathrm{S}(Q)$, and (b) neutron total pair correlation, $\mathrm{G}(r)$, data for $\mathrm{Bi}_{7} \mathrm{WO}_{13.5}$ at $900{ }^{\circ} \mathrm{C}$, fitted by RMC analysis. Observed (crosses), calculated (line) and difference (lower) profiles are shown. 
(a)

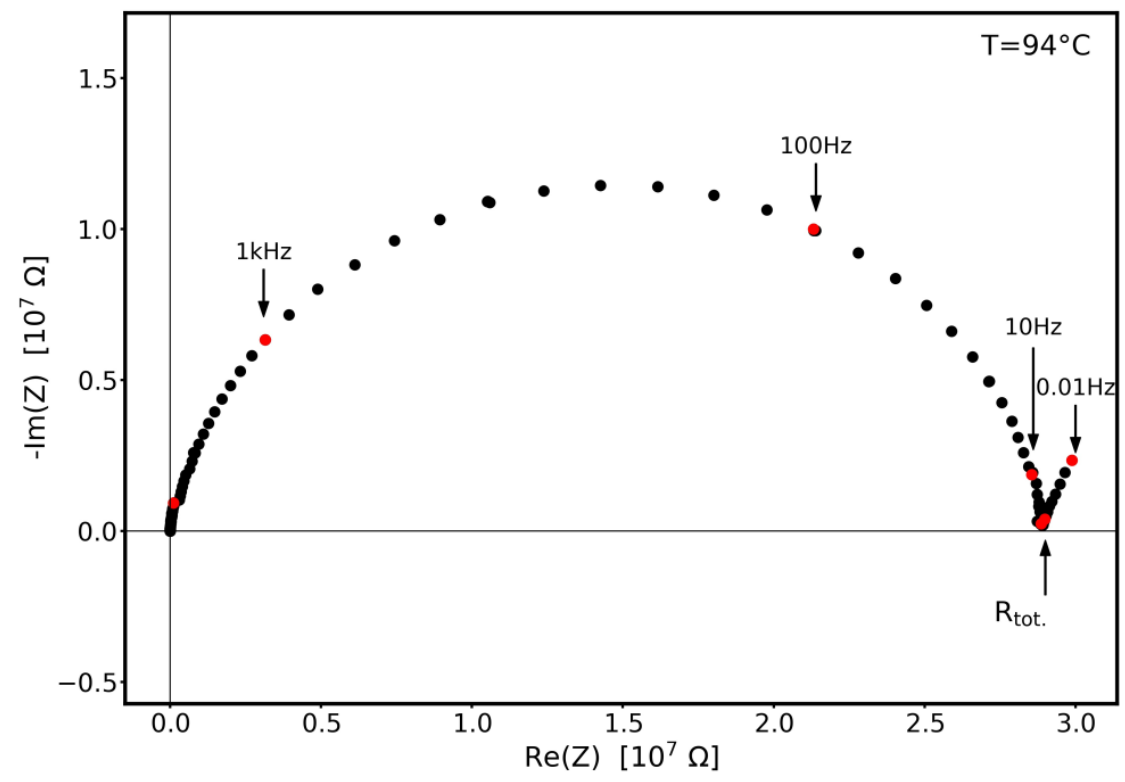

(b)

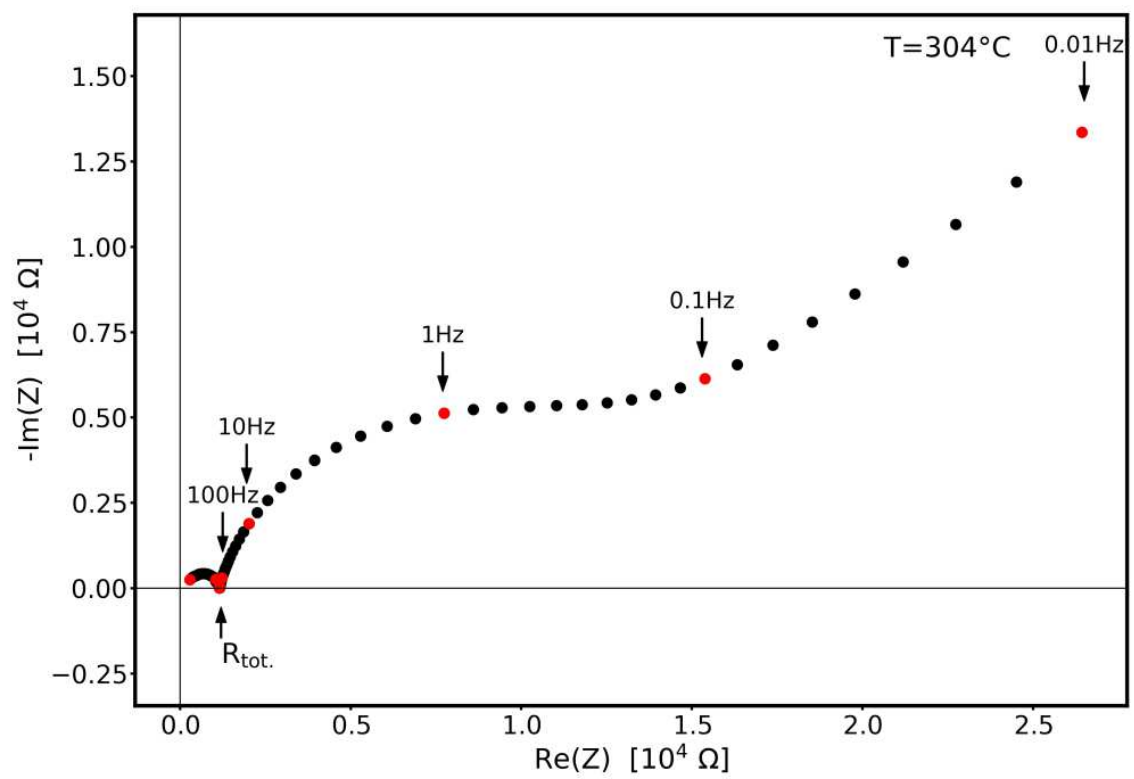

Fig. S5. Representative impedance spectra for $\mathrm{Bi}_{7} \mathrm{WO}_{13.5}$ at (a) $94^{\circ} \mathrm{C}$ and (b) $304^{\circ} \mathrm{C}$. Selected frequencies are indicated. 
Table S1. Contributions of ionic $\left(\sigma_{\text {ion }}\right)$ and electronic $\left(\sigma_{\mathrm{e}}\right)$ conductivities to total conductivity $\left(\sigma_{\text {tot }}\right)$, along with ionic transference number $t_{\text {ion }}$, as functions of temperature for $\mathrm{Bi}_{7} \mathrm{WO}_{13.5}$.

\begin{tabular}{|c|c|c|c|c|}
\hline $\begin{array}{c}\text { Temperature } \\
{\left[{ }^{\circ} \mathrm{C}\right]}\end{array}$ & $\begin{array}{c}\sigma_{\text {tot. }} \\
{\left[\mathrm{Scm}^{-1}\right]}\end{array}$ & $\begin{array}{c}\sigma_{\mathrm{e} .} \\
{\left[\mathrm{Scm}^{-1}\right]}\end{array}$ & $\begin{array}{c}\sigma_{\text {ion. }} \\
{\left[\mathrm{Scm}^{-1}\right]}\end{array}$ & $t_{\text {ion }}$ \\
\hline 832 & $1.9222 \times 10^{-1}$ & $3.0013 \times 10^{-3}$ & $1.8922 \times 10^{-1}$ & 0.984 \\
\hline 801 & $1.7405 \times 10^{-1}$ & $2.1473 \times 10^{-3}$ & $1.7199 \times 10^{-1}$ & 0.988 \\
\hline 740 & $9.9572 \times 10^{-2}$ & $1.0749 \times 10^{-3}$ & $9.8452 \times 10^{-2}$ & 0.989 \\
\hline 709 & $7.7834 \times 10^{-2}$ & $6.9437 \times 10^{-4}$ & $7.7140 \times 10^{-2}$ & 0.991 \\
\hline 679 & $6.1402 \times 10^{-2}$ & $4.5650 \times 10^{-4}$ & $6.0946 \times 10^{-2}$ & 0.993 \\
\hline 617 & $3.3543 \times 10^{-2}$ & $1.9223 \times 10^{-4}$ & $3.3351 \times 10^{-2}$ & 0.994 \\
\hline 587 & $2.4479 \times 10^{-2}$ & $1.1913 \times 10^{-4}$ & $2.4360 \times 10^{-2}$ & 0.995 \\
\hline 555 & $1.7684 \times 10^{-2}$ & $7.1731 \times 10^{-5}$ & $1.7626 \times 10^{-2}$ & 0.996 \\
\hline 525 & $1.2560 \times 10^{-2}$ & $4.2769 \times 10^{-5}$ & $1.2531 \times 10^{-2}$ & 0.997 \\
\hline 494 & $0.8668 \times 10^{-2}$ & $1.5256 \times 10^{-5}$ & $0.8654 \times 10^{-2}$ & 0.998 \\
\hline
\end{tabular}

